\title{
Notas Cietíficas \\ Dinâmica da serapilheira e transferência de nitrogênio ao solo, em plantios de Pseudosamanea guachapele e Eucalyptus grandis
}

Fabiano de Carvalho Balieiro(1), Avílio Antônio Franco(2), Marco Gervásio Pereira(3), Eduardo Francis Carneiro Campello(2), Luiz Eduardo Dias ${ }^{(4)}$, Sérgio Miana de Faria( ${ }^{(2)}$ e Bruno José Rodrigues Alves ${ }^{(2)}$

(1)Pesagro-Rio, Alameda São Boaventura, 770, CEP 24120-191 Niterói, RJ. E-mail: carvalieiro@pesagro.rj.gov.br (2)Embrapa Agrobiologia, CEP 23890-000 Seropédica, RJ. E-mail: avilio@cnpab.embrapa.br (3)Universidade Federal Rural do Rio de Janeiro, Dep. de Solos, CEP 23890-000 Seropédica, RJ. E-mail: gervasio@ufrj.br (4)Universidade Federal de Viçosa, Dep. de Solos, Av. P.H. Rolfs, s/no , CEP 37560000 Viçosa, MG. E-mail: Idias@ufv.br

Resumo - Este trabalho teve como objetivo avaliar a deposição de serapilheira e a transferência de $\mathrm{N}$ associada às folhas e folíolos desse resíduo em plantios puros e consorciado de guachapele (Pseudosamanea guachapele) e eucalipto (Eucalyptus grandis), aos sete anos de idade, em Seropédica, RJ. No ano de avaliação (2000/2001) a deposição anual de serapilheira nos diferentes plantios não diferiu significativamente: $12,75 \mathrm{Mg} \mathrm{ha}^{-1}$ (guachapele); 11,84 $\mathrm{Mg} \mathrm{ha}^{-1}$ (eucalipto) e 12,44 Mg ha-1 (consorciado). Mesmo com pequena participação na composição da serapilheira em plantio consorciado ( $11 \%$ do total depositado), a leguminosa proporciona redução no tempo médio de residência dos resíduos no solo de 0,3 ano, comparativamente ao plantio puro de eucalipto.

Termos para indexação: ciclagem de nutrientes, consórcio florestal.

\section{Contribution of litter and nitrogen to soil under Pseudosamanea guachapele and Eucalyptus grandis plantations}

Abstract - The litter deposition and nitrogen content on litter leaves were studied on seven years old pure and 1:1 mixed stand of guachapele (Pseudosamanea guachapele) and eucalyptus (Eucalyptus grandis). There was no difference in litter deposition among species in pure or mixed crop: $12.75 \mathrm{Mg} \mathrm{ha}^{-1}$ for guachapele, $11.84 \mathrm{Mg} \mathrm{ha}^{-1}$ for the eucalyptus and $12.44 \mathrm{Mg} \mathrm{ha}^{-1}$ for the mixed crop. The legume three contribution to the mixed stand was only $11 \%$ of the total, but reduced by 0.3 year the time of residue residence on the soil.

Index terms: nutrient cycle, mixed forest.

A dinâmica da serapilheira e de seus nutrientes, representada pela entrada via deposição e saída via decomposição/mineralização é essencial à manutenção de florestas ou plantios florestais. Porém, diversos fatores estão relacionados com o sincronismo com que esses fenômenos ocorrem, sendo a composição química desses resíduos, a precipitação pluvial e a temperatura, os de maior representatividade (Thomas \& Asakawa, 1993; Landberg \& Gower, 1997). Fatores como a idade, a densidade de plantio, o estágio sucessional, a espécie estudada também se relacionam com a intensidade ou magnitude com que as transformações do resíduo vegetal aportado ao solo ocorrem (Leite, 1996; Negi \& Sharma, 1996; Mesquita et al., 1998).

A importância do $\mathrm{N}$ na dinâmica da matéria orgânica do solo é inquestionável, estando este nutriente relacionado diretamente com a velocidade de mineralização da mesma (Thomas \& Asakawa, 1993; Froufe, 1999) e sua estabilização no solo (Tarré et al., 2001; Sisti et al., 2004). Desta forma, a inserção de espécies fixadoras de $\mathrm{N}$ atmosférico em solos oxídicos e de baixa fertilidade, em regiões com baixos recursos financeiros para aquisição de fertilizantes ou insumos, pode ser interessante no manejo da cultura do eucalipto, pois a introdução desse elemento por meio da serapilheira, pode também aumentar o estoque de nutrientes para os cultivos em sucessão ou rotação (Brinkley et al., 1992; Balieiro et al., 2002).

Apesar de poucos trabalhos contemplarem o consórcio do eucalipto com leguminosas arbóreas no Brasil, é nítida a infinidade de combinações que a biodiversidade tropical oferece de se trabalhar em prol de um manejo sustentável da floresta plantada. Este trabalho se desenvolveu com base no potencial que a leguminosa 
Pseudosamanea guachapele Kunth (Harms) (guachapele) possui em ciclar nutrientes (Froufe, 1999; Balieiro, 2002) e manter a produtividade do eucalipto (Balieiro et al., 2002).

O objetivo deste trabalho foi estudar a dinâmica da serapilheira e de transferência de $\mathrm{N}$ ao solo em plantios puros e consorciado de guachapele e eucalipto com sete anos.

O experimento foi realizado durante os meses de agosto de 2000 a julho de 2001, no Campo Experimental da Embrapa Agrobiologia, em Seropédica, RJ (220 46' de latitude sul e $43^{\circ} 41^{\prime}$ de longitude oeste; $33 \mathrm{~m}$ de altitude). A média pluvial anual é de $1.250 \mathrm{~mm}$ com temperatura entre $16^{\circ} \mathrm{C}$ (junho-julho) e $32^{\circ} \mathrm{C}$ (janeiro-março). A umidade relativa média anual é de $73 \%$.

O experimento foi estabelecido em um Planossolo da série ecologia (Ramos et al., 1973) cujas características são a presença de um horizonte superficial de textura arenosa, que no local do experimento alcança profundidades superiores a 1,30 m, baixa CTC e baixos teores de matéria orgânica e nutrientes. Antes da implantação do experimento, foram coletadas amostras de solo $(0-20 \mathrm{~cm})$ em 1993, cujos resultados da análise química foram: $\mathrm{pH}, 5,3 ; \mathrm{Al}^{3+}, 0,2 \mathrm{cmol}_{\mathrm{c}} \mathrm{dm}^{-3} ; \mathrm{Ca}^{2+}+\mathrm{Mg}^{2+}$ trocáveis, 1,3 $\mathrm{cmol}_{\mathrm{c}} \mathrm{dm}^{-3}$, extraídos com $\mathrm{KCl} 1 \mathrm{~mol} \mathrm{~L}^{-1}$; P, 10,3 $\mathrm{mg} \mathrm{dm}^{-3} \mathrm{e} \mathrm{K}, 21 \mathrm{mg} \mathrm{dm}^{-3}$, extraídos por Mehlich1. As análises foram feitas conforme Embrapa (1997). A área, com relevo plano a suave ondulado, foi utilizada como pastagem por mais de 10 anos, antes que os plantios fossem estabelecidos.

Plantios puros e um consorciado das espécies guachapele e eucalipto foram realizados em 1993, com mudas de três meses de idade. As sementes de guachapele foram submetidas à inoculação de estirpes selecionadas de rizóbio (BR6205 e BR6821). Ambas as espécies receberam inóculo de esporos + hifas dos fungos micorrízicos Glomus clarum e Gigaspora margarita, aplicando-se 10 g de solo contendo o inóculo e sobre ele a semente que foi imediatamente coberta com solo.

Os talhões relativos a cada tratamento possuíam $2.500 \mathrm{~m}^{2}$, e o espaçamento de plantio foi de $3 \mathrm{~m}$ entre linhas e de $1 \mathrm{~m}$ nas linhas. O plantio consorciado foi efetuado alternando uma linha de eucalipto com outra de guachapele. Por ocasião do plantio, cada cova recebeu $100 \mathrm{~g}$ de fosfato de rocha $+10 \mathrm{~g}$ de FTE BR-12. A 0,5 m das linhas de plantio das mudas de eucalipto foram aplicados, adicionalmente, $25 \mathrm{~g}$ por metro linear de sulfato de amônio. Não foi realizado desbaste nem adubação adicional.

O diâmetro médio à altura do peito (DAP) do quachapele foi de 10,1 e $8,3 \mathrm{~cm}$ e do eucalipto foi de 12,4 e $16,0 \mathrm{~cm}$ nos plantios puros e consorciado, respectivamente.

A deposição mensal de serapilheira em cada plantio foi quantificada mediante a instalação aleatória de seis coletores na parte central de cada parcela com coleta mensal do material. Cada coletor de serapilheira possuía $1 \mathrm{~m}^{2}$, forrado internamente com tela de náilon com malha de $1 \mathrm{~mm}$. Em três ocasiões, ao longo do ano, os coletores foram mudados de posição dentro da área útil da parcela (1.000 $\mathrm{m}^{2}$ centrais), visando diminuir efeito de local. Os diferentes componentes da serapilheira depositados - folhas, galhos com diâmetro $<3 \mathrm{~cm}$, cascas, estruturas reprodutivas e o refugo (material não identificado) - foram secados em estufa de ventilação forçada a $70^{\circ} \mathrm{C}$ por 72 horas, separados e pesados. Na mesma ocasião, amostras de folhas e folíolos, de agora em diante tratadas apenas como folhas, representativas de cada plantio e estação do ano, cada qual com seis repetições, foram caracterizadas quanto aos seus teores de $\mathrm{N}$ pelo método da destilação a vapor (Kjeldahl), após mineralização com ácido sulfúrico (Bremner \& Mulvaney, 1982).

O tempo médio de residência (TMR, em anos) da serapilheira no solo, sob cada plantio, foi estimado conforme Landsberg \& Gower (1997), a partir da razão entre a massa média anual de serapilheira existente sobre o solo (manta orgânica) $\left(\mathrm{Mg} \mathrm{ha}^{-1}\right)$ e a massa do material depositado durante o ano inteiro $\left(\mathrm{Mg} \mathrm{ha}^{-1} \mathrm{ano}^{-1}\right)$. Para tanto, a manta orgânica sobre o solo de cada plantio foi monitorada também mensalmente por meio da coleta aleatória de seis amostras, constituindo-se cada uma delas uma repetição. Utilizou-se na coleta das amostras uma sonda metálica de $0,0625 \mathrm{~m}^{2}$. As amostras foram secadas até peso constante.

As diferenças entre os totais depositados e acumulados sobre o solo, em cada tratamento, bem como entre os teores de $\mathrm{N}$ das folhas senescentes de cada espécie foram testadas pelo teste $\mathrm{t}$ a $5 \%$ de probabilidade, pelo programa SIGMASTAT.

Durante o ano de avaliação, aportaram ao solo 12,75, 11,84 e 12,44 $\mathrm{Mg} \mathrm{ha}^{-1}$ de serapilheira, nos plantios puros de guachapele e de eucalipto e no consorciado, respectivamente. A deposição ao longo do ano não apresentou tendência diferenciada entre os plantios, embora as curvas obtidas nos plantios nos quais o eucalipto estava 
presente fossem mais próximas (Figura 1). De modo geral, as deposições predominaram nos meses de dezembro, janeiro e fevereiro. As temperaturas mais elevadas e a baixa capacidade de retenção de umidade do Planossolo onde os plantios foram estabelecidos (Ramos et al., 1973; Balieiro, 2002), certamente, imprimiram um estresse hídrico às espécies, que em resposta, diminuíram sua superfície de transpiração, via queda de folhas.

A massa da manta orgânica nos plantios, por sua vez, apresentou menores variações ao longo do ano (Figura 2). Esse resultado se deve provavelmente à taxa de decomposição mais acelerada nos meses mais chuvosos e mais reduzida nos mais secos.

A maior quantidade de serapilheira acumulada sobre o solo no plantio de eucalipto $\left(16,6 \mathrm{t} \mathrm{ha}^{-1}\right)$ evidencia que a elevada contribuição de material lenhoso (galhos cascas) para a serapilheira produzida pode estar aumentando o tempo médio de decomposição dos resíduos no solo. A participação porcentual desses resíduos lenhosos no plantio consorciado também foi elevada (Tabela 1) porém a massa da manta no plantio consorciado permaneceu sempre em valores inferiores ao detectado onde só havia eucalipto (Figura 2). Esse fato provavelmente foi influenciado pelo maior aporte de $\mathrm{N}$ via serapilheira da leguminosa, aumentando a velocidade de decomposição dos resíduos existentes sobre o solo, tanto os provenientes da leguminosa quanto os do eucalipto.

As folhas e os galhos foram os componentes de maior participação em peso e em porcentual no total depo-



Figura 1. Deposição mensal de serapilheira nos plantios puros de Pseudosamanea guachapele (o) e Eucalyptus grandis $(\bullet)$ e no consorciado ( $\mathbf{\Lambda})$. Barras em cada ponto representam a

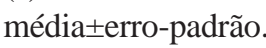

sitado pelas espécies, independentemente do plantio, apesar de ter havido tendência de diminuição relativa do componente folha e aumento relativo do componente galho, de ambas as espécies, em condição de plantio consorciado. Os frutos, juntamente com o refugo, ou seja, material não identificado, representaram menos de $7 \%$ do total depositado nos diferentes plantios. Constatouse participação significativa da casca do eucalipto no total aportado na área do plantio puro $(11,9 \%)$ e do consorciado $(13,9 \%)$ e a ausência desse componente oriundo da guachapele no plantio consorciado.

As diferenças nos teores de $\mathrm{N}$ nas folhas recém-caídas de cada espécie, nas duas diferentes condições de plantio foram significativas (Tabela 2). Os menores teores nos tecidos senescentes de ambas as espécies, no plantio consorciado, podem indicar que a ciclagem bioquímica ou interna tenha sido intensificada pelo maior acúmulo de nutrientes na biomassa lenhosa das espécies nessa condição de plantio (Balieiro, 2002). As diferenças entre as espécies se relacionam com a origem do $\mathrm{N}$ absorvido por cada uma delas (leguminosa: $\mathrm{N}$ atmosférico e para o eucalipto: $\mathrm{N}$ mineral $\left(\mathrm{NH}_{4}{ }^{+} \mathrm{e}\right.$ $\mathrm{NO}_{3}{ }^{-}$.

A quantidade de $\mathrm{N}$ aportada ao solo do plantio puro de guachapele $\left(248,11 \mathrm{~kg} \mathrm{ha}^{-1}\right)$ foi superior à dos demais tratamentos como também às quantidades relatadas por Costa (1998), Froufe (1999) e Andrade et al. (2000) para diversas espécies leguminosas em Seropédica. No sistema consorciado foi observado aporte de $66,1 \mathrm{~kg} \mathrm{ha}^{-1}$ de $\mathrm{N}$ e de $58,0 \mathrm{~kg} \mathrm{ha}^{-1}$ no plantio

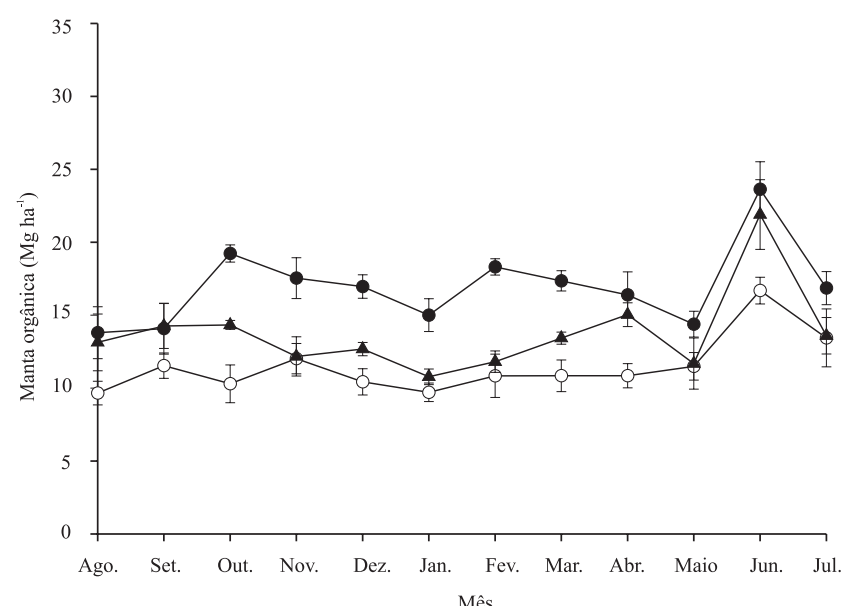

Figura 2. Manta orgânica sobre o solo nos plantios puros de Pseudosamanea guachapele (o) e Eucalyptus grandis (•) e no consorciado (ム). Barras em cada ponto representam a

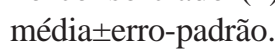


Tabela 1. Massa total incidente dos diferentes componentes formadores da serapilheira depositada nos plantios puros e consorciado de guachapele e eucalipto e suas respectivas participações porcentuais (números entre parênteses) no total depositado no período em estudo.

\begin{tabular}{lcccccc}
\hline Tratamento & Folha & Galho & Casca & $\begin{array}{c}\text { Fruto } \\
\text { - }\end{array}$ & Refugo & Total $^{(1)}$ \\
\hline Guachapele & $10,846(85,1)$ & $1,582(12,4)$ & $0,103(0,8)$ & $0,034(0,3)$ & $0,186(1,5)$ & $12,750 \mathrm{a}$ \\
Eucalipto & $6,826(57,7)$ & $2,773(23,4)$ & $1,406(11,9)$ & $0,449(3,8)$ & $0,385(3,3)$ & $11,840 \mathrm{a}$ \\
Consórcio & $7,015(56,4)$ & $3,042(24,5)$ & $1,732(13,9)$ & $0,400(3,2)$ & $0,248(2,0)$ & $12,437 \mathrm{a}$ \\
\hline
\end{tabular}

${ }^{(1)}$ Médias seguidas da mesma letra não diferem entre si pelo teste t a $5 \%$ de probabilidade.

Tabela 2. Teor médio de N (média \pm erro-padrão) nas folhas da serapilheira nos diferentes plantios avaliados ${ }^{(1)}$.

\begin{tabular}{lccrc}
\hline Estação $^{(2)}$ & Guachapele & Guachapele-consórcio & Eucalipto & Eucalipto-consórcio \\
& - & $11,48 \pm 0,20 \mathrm{~b}$ & $9,53 \pm 0,11 \mathrm{a}$ & $6,30 \pm 0,03 \mathrm{~b}$ \\
\hline Verão & $22,33 \pm 0,30 \mathrm{a}$ & $14,62 \pm 0,19 \mathrm{~b}$ & $12,32 \pm 0,07 \mathrm{a}$ & $8,50 \pm 0,11 \mathrm{~b}$ \\
Outono & $21,43 \pm 0,22 \mathrm{a}$ & $13,56 \pm 0,17 \mathrm{~b}$ & $6,99 \pm 0,15 \mathrm{~b}$ & $7,70 \pm 0,14 \mathrm{a}$ \\
Primavera & $25,14 \pm 0,08 \mathrm{a}$ & $16,64 \pm 0,31 \mathrm{~b}$ & $5,77 \pm 0,19 \mathrm{a}$ & $6,13 \pm 0,07 \mathrm{a}$ \\
Inverno & $22,23 \pm 0,55 \mathrm{a}$ & &
\end{tabular}

${ }^{(1)}$ Médias seguidas da mesma letra, na linha, dentro de cada espécie, não diferem entre si pelo teste t a $1 \%$ de probabilidade. ${ }^{(2)}$ Verão: mistura da serapilheira dos meses de dezembro, janeiro e fevereiro; outono: março, abril e maio; inverno: junho, julho e agosto; primavera: setembro, outubro e novembro.

puro de eucalipto, evidenciando o benefício da leguminosa naquele sistema. Essa contribuição parece pequena, mas levando-se em consideração a participação porcentual do material aportado pela leguminosa (de apenas 11\%) e da importância que o $\mathrm{N}$ possui na atividade biológica e estabilização da matéria orgânica do solo (Sisti et al., 2004), pode-se afirmar que plantios consorciados de eucalipto com leguminosas poderiam aumentar o acúmulo de matéria orgânica do solo, principalmente naqueles de textura arenosa.

Com uma massa média de manta de $16,6 \mathrm{Mg}^{-1}$, valor esse bem superior ao dos demais plantios, pode-se concluir que os resíduos do plantio de eucalipto apresentavam uma taxa de decomposição mais baixa no solo, resultando em um TMR de 1,43 ano para a espécie. A introdução de um material rico em $\mathrm{N}$ ao solo do plantio consorciado, via queda de resíduos da leguminosa foi determinante na redução do TMR dos resíduos depositados naquele plantio. Com um TMR estimado em 1,10 ano, o resíduo desse plantio acabou sendo mantido em menor massa sobre o solo $\left(13,79 \mathrm{Mg} \mathrm{ha}^{-1}\right)$. O resíduo do plantio da leguminosa, com teores mais elevados de $\mathrm{N}$ apresentou o menor TMR, de 0,9 ano.

O plantio consorciado de Eucalyptus grandis Pseudosamanea guachapele em solos arenosos deve ser incentivado, pois quando comparado com o plantio apenas de eucalipto, a quantidade de $\mathrm{N}$ aportada ao solo e a velocidade de mineralização dos resíduos é incrementada, o que pode representar ganhos futuros em termos de fertilidade e sincronismo à demanda nutricional do eucalipto. Além disso, a produtividade do eucalipto é ligeiramente superior no plantio consorciado em relação ao plantio puro da espécie, onde o número de plantas é o dobro do plantio consorciado.

\section{Agradecimentos}

À Faperj pela bolsa concedida a Fabiano de Carvalho Balieiro; ao CNPq pelo apoio financeiro.

\section{Referências}

ANDRADE, A.B.; COSTA, G.S.; FARIA, S.M. Deposição e decomposição da serapilheira em povoamentos de Mimosa caesalpiniifolia, Acacia mangium e Acacia holosericea com quatro anos de idade em Planossolo. Revista Brasileira de Ciência do Solo, v.24, p.777-785, 2000

BALIEIRO, F.C. Dinâmica de nutrientes e da água em plantios puros e consorciados de Pseudosamanea guachapele Dugand e Eucalyptus grandis W. Hill ex Maiden. 2002. 92p. Tese (Doutorado) - Universidade Federal Rural do Rio de Janeiro, Seropédica.

BALIEIRO, F.C.; FRANCO, A.A.; FONTES, R.L.F.; DIAS, L.E.; CAMPELLO, E.F.C. Accumulation and distribution of aboveground biomass and nutrients under pure and mixed stands of Pseudosamanea guachapele Dugand and Eucalyptus grandis W. Hill ex Maiden. Journal of Plant Nutrition, v.25, p.2639-2654, 2002. 
BREMNER, J.M.; MULVANEY, C.S. Nitrogen - Total. In: PAGE A.L. (Ed.). Methods of soil analysis. $2^{\text {nd }}$ ed. Madison: Soil Science Society of America, 1982. pt.2, p.595-624

BRINKLEY, D.; DUNKIN, K.A.; DEBELL, D.S.; RYAN, M.G Production and nutrient cycling in mixed plantation of Eucalyptus and Albizia in Hawaii. Forest Science, v.38, p.393-408, 1992.

COSTA, G.S. Ciclagem de nutrientes em uma área degradada revegetada com leguminosas arbóreas e em um fragmento florestal em crescimento secundário (capoeira). 1998. 87p. Dissertação (Mestrado) - Universidade Federal Fluminense, Niterói EMBRAPA. Centro Nacional de Pesquisa de Solos (Rio de Janeiro, RJ). Manual de métodos de análise de solo. 2.ed. Rio de Janeiro, 1997. 212 p.

FROUFE, L.C.M. Decomposição de serapilheira e aporte de nutrientes em plantios puros e consorciados de Eucalyptus grandis Maiden, Pseudosamanea guachapele Dugand e Acacia mangium Willd. 1999. 73p. Dissertação (Mestrado) - Universidade Federal Rural do Rio de Janeiro, Seropédica.

LANDBERG, J.J.; GOWER, S.T. Applications of physiological ecology to forest management. San Diego: Academic, 1997. p.89124.

LEITE, F.P. Crescimento, relações hídricas, nutricionais e lumínicas em povoamentos de Eucalyptus grandis em diferentes densidades populacionais. 1996. 90p. Dissertação (Mestrado) Universidade Federal de Viçosa, Viçosa.
MESQUITA, R.C.G.; WORKMAN, S.W.; NEELY, C.N. Slow litter decomposition in a Cecropia: dominated secondary forest of central Amazonia. Soil Biology \& Biochemistry, v.30, p.167-175, 1998. NEGI, J.D.S. SHARMA, S.C. Mineral nutrition and resourse conservation in Eucalyptus plantation and other forest covers in India. In: ATTWILL, P.M.; ADAMS, M.A. (Ed.). Nutrition of eucalyptus. Collingwood: Commonwealth Scientific \& Industrial Research Organization, 1996. p.399-416.

RAMOS, D.P.; CASTRO, A.F. de; CAMARGO, M.N. Levantamento detalhado de solos da área da Universidade Federal Rural do Rio de Janeiro. Pesquisa Agropecuária Brasileira, Série Agronomia, v.8, p.1-27, 1973.

SISTI, C.P.J.; SANTOS, H.P.; KOHHANN, R.; ALVES, B.J.R.; URQUIAGA, S.; BODDEY, R.M. Change in carbon and nitrogen stocks in soil under 13 years of conventional or zero tillage in southern Brazil. Soil and Tillage Research, v.76, p.39-58, 2004.

TARRÉ, R.; MACEDO, R.; CANTARUTTI, R.B.; REZENDE, C.P.; PEREIRA, J.M.; FERREIRA, E.; ALVES, B.J.R.; URQUIAGA, S.; BODDEY, R.M. The effects of the presence of a forage legume on nitrogen and carbon levels in soils under brachiaria forage legume on nitrogen and carbon levels in soils under brachiaria
pasture in the Atlantic Forest region of the south of Bahia, Brazil. Plant and Soil, v.234, p.15-26, 2001.

THOMAS, R.J.; ASAKAWA, N.M. Decomposition of leaf litter from tropical forage grasses and legumes. Soil Biology \& Biochemistry, v.25, p.1351-1361, 1993.

$\overline{\text { Recebido em } 15 \text { de agosto de } 2003 \text { e aprovado em } 4 \text { de março de } 2004}$ 